\title{
Apoptosis modulates protective immunity to the pathogenic fungus Histoplasma capsulatum
}

\author{
Holly L. Allen and George S. Deepe Jr. \\ Division of Infectious Diseases, Veterans Affairs Hospital, University of Cincinnati College of Medicine, Cincinnati, Ohio, USA.
}

\begin{abstract}
Pathogen-induced apoptosis of lymphocytes is associated with increased susceptibility to infection. In this study, we determined whether apoptosis influenced host resistance to the fungus Histoplasma capsulatum. The level of apoptotic leukocytes progressively increased in the lungs of naive and immune mice during the course of $H$. capsulatum infection. T cells constituted the dominant apoptotic population. Apoptosis was diminished in $H$. capsulatum-infected $g l d / g l d$ and TNF- $\alpha$-deficient mice; concomitantly, the fungal burden exceeded that of controls. Treatment of naive and $H$. capsulatum-immune mice with caspase inhibitors decreased apoptosis but markedly enhanced the severity of infection. Administration of a proapoptotic dose of suramin diminished the fungal burden. The increased burden in recipients of a caspase inhibitor was associated with elevations in IL-4 and IL-10 levels. In the absence of either of these cytokines, caspase inhibition suppressed apoptosis but did not increase the fungal burden. Thus, apoptosis is a critical element of protective immunity to $H$. capsulatum. Production of IL-4 and IL-10 is markedly elevated when apoptosis is inhibited, and the release of these cytokines exacerbates the severity of infection.
\end{abstract}

\section{Introduction}

Infection with the dimorphic fungus $H$. capsulatum is initiated by coincidental inhalation of microconidia and mycelial fragments that convert into the pathogenic yeast phase within hours to days after settling in lungs. The latter fungal elements proliferate within cells of the mononuclear phagocyte system until activation of cellmediated immunity halts intracellular replication (1). The efficacy of the protective immune response requires an orchestration of numerous cellular and soluble effectors. $\mathrm{CD}^{+}$and $\mathrm{CD}^{+} \mathrm{T}$ cells contribute to the clearance of the organism in both primary and secondary infection, although their influence differs in the 2 phases (2-5). IL-12, IFN- $\gamma$, GM-CSF, and TNF- $\alpha$ are known to promote the protective immune response of mice during primary infection (6-15). In secondary histoplasmosis, only the latter cytokine is essential for mice to survive. These findings suggest that among the cytokines that regulate protective immunity, TNF- $\alpha$ exerts the preeminent influence on host defenses. This assertion is supported by the recent spate of cases of disseminated histoplasmosis among patients who receive inhibitors of TNF- $\alpha$ activity $(16,17)$.

Among the many immunological elements that could modulate the course of infection with $H$. capsulatum is apoptosis, or programmed cell death. This process is critically important in the developmental biology of multicellular organisms, and it is a principal regulator of the specificity of the immune system (18-24). In recent years, several reports have shown that inhibition of apoptosis may influence the outcome of infection with intracellular and extracellular pathogens and/or modulate the inflammatory response $(22,25,26)$.

Nonstandard abbreviations used: Boc-D-FMK, benzyloxycarbonyl-Asp(OMe)-fluoromethyl ketone; TNFR1, TNF receptor 1; z-DQMD-FMK, Asp-Gln-Met-Asp-fluoromethyl ketone; Z-FA-FMK, $N$-benzyloxycarbonyl-Phe-Asp-fluoromethyl ketone.

Conflict of interest: The authors have declared that no conflict of interest exists.

Citation for this article: J. Clin. Invest. 115:2875-2885 (2005).

doi:10.1172/JCI25365.
As part of an ongoing series of studies of the mechanisms by which TNF- $\alpha$ contributes to host defenses, we initiated a study to explore the role of apoptosis, since this cytokine is an important trigger of this process (27-29). Our results indicate that apoptosis is a prominent feature of lung leukocytes in mice infected i.n. with $H$. capsulatum yeast cells and $T$ cells constitute the vast majority of apoptotic cells. The magnitude of apoptosis was regulated not only by TNF- $\alpha$ and its cognate receptor TNF receptor 1 (TNFR1) but also by Fas-Fas ligand interaction. Moreover, caspase inhibition of apoptosis was associated with a profoundly impaired protective immune response. We conclude that apoptosis modulates the severity of infection.

\section{Results}

H. capsulatum infection is associated with a progressive increase in the proportion of apoptotic lung leukocytes. Cells from lungs of mice infected with $H$. capsulatum were assessed for apoptosis using a flow cytometry-based TUNEL assay. Naive animals were infected with $2 \times 10^{6}$ yeast cells i.n., and lung leukocytes were analyzed prior to infection (day 0 ) and at days 7,14 , and 21 after infection. The percentage of apoptotic cells in the lungs of uninfected mice was less than $5 \%$. By day 7 of infection, the percentage of apoptotic cells had increased to $23.5 \%$, and by day 21 this value was $60.3 \%$ (Figure 1A).

In parallel experiments, we assessed the proportion of apoptotic leukocytes in lungs of mice with secondary $H$. capsulatum infection. Mice were challenged with $10^{4}$ yeast cells i.n., and 8 weeks later, they were rechallenged with $2 \times 10^{6}$ yeast cells. At day 0 , the percentage of apoptotic cells was less than $5 \%$, similar to that in naive animals. Following infection, there was a progressive increase from days 7 to 21 in the percentage of apoptotic cells (Figure 1B).

Apoptosis is not strictly dependent on inoculum size. Mice were infected with increasing numbers of $H$. capsulatum yeast cells i.n., and at day 7 after infection, the percentage of apoptotic lung leu- 

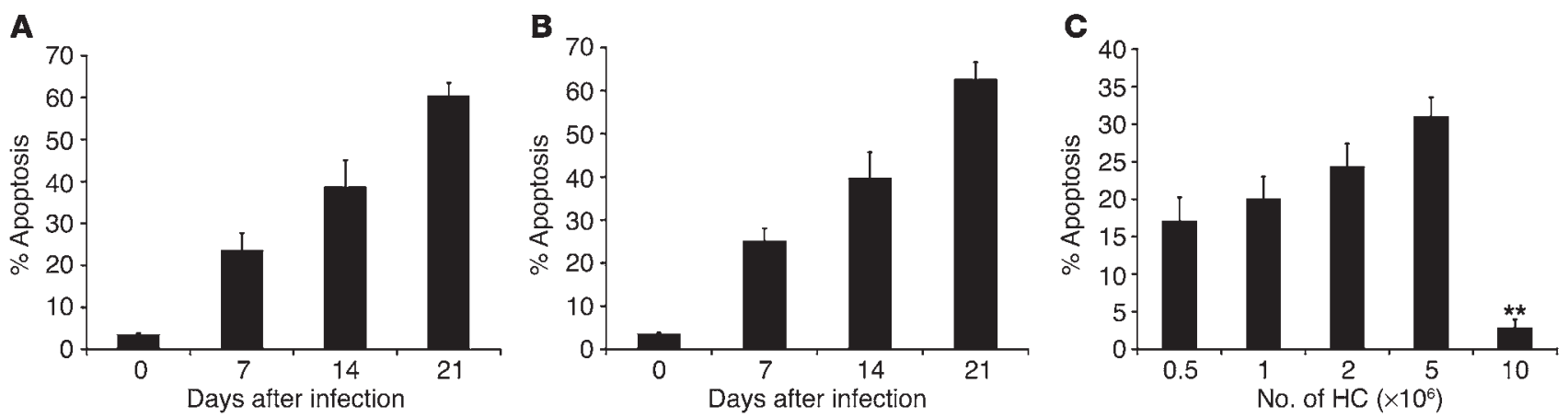

Figure 1

Apoptosis of lung leukocytes isolated from C57BL/6 mice infected with $H$. capsulatum. (A) In primary infection, mice were infected with $2 \times 10^{6}$ yeast cells i.n. (B) In secondary infection, mice were infected with $10^{4}$ yeast cells i.n. and 49 days later challenged with $2 \times 10^{6} \mathrm{H}$. capsulatum yeast cells i.n. Apoptosis was assessed at $0,7,14$, and 21 days after infection by flow cytometry. Data represent mean \pm SEM of 6 animals per group. (C) Mice were infected with increasing numbers of $H$. capsulatum yeast cells (HC). Apoptosis was assessed at 7 days after infection. Data represent mean \pm SEM of 6 animals per group. ${ }^{\star \star} P<0.01$ compared with each of the inocula. Data from 1 of 2 experiments are shown.

kocytes was assessed (Figure 1C). There was a slight increase in the response from $0.5 \times 10^{6}$ to $5 \times 10^{6}$, although the differences between the different challenges were not statistically significant $(P>0.05)$. On the other hand, the apoptotic response to $10 \times 10^{6}$ yeast cells, which is associated with a high mortality (30), was markedly diminished $(P<0.01)$. Thus, the apoptotic response is partially dependent on the challenge size.

Phenotype of apoptotic cells. The phenotype of lung leukocytes that underwent apoptosis was assessed using 2-color flow cytometry during the course of infection. We restricted analysis to T cells, macrophages, and neutrophils, since these cell populations constitute the major cellular mediators of protective immunity in experimental $H$. capsulatum $(2,10,31)$. To calculate the quantity of each cell population that was apoptotic, we divided the percentage of each apoptotic cell population by the total percentage of apoptotic cells. Representative histograms are shown in Figure 2, A and B. In pri- mary infection, $\mathrm{CD}^{+}$cells constituted the overwhelming majority of apoptotic cells at days 7 through 21 after infection (Figure 2E). The proportion of neutrophils that were apoptotic was small $(\sim 5 \%)$ and that of macrophages was negligible (1\%). This finding was also true for secondary H. capsulatum infection (Figure 2F).

Although the proportions differed, it is possible that the absolute numbers did not. At each time point of primary or secondary infection, the number of apoptotic $\mathrm{CD}^{+}$cells exceeded that of neutrophils. For example, the mean number $( \pm$ SEM) of apoptotic $\mathrm{CD}^{+}$cells at day 7 of primary infection $\left(13.28 \times 10^{5} \pm 0.83 \times 10^{5}\right)$ was greater $(P<0.01)$ than the number of apoptotic neutrophils $\left(2.9 \times 10^{5} \pm 0.09 \times 10^{5}\right)$. On day 7 of secondary infection, the number of apoptotic $\mathrm{CD}^{+}$cells $\left(10.7 \times 10^{6} \pm 0.6 \times 10^{6}\right)$ was higher $(P<0.01)$ than that of neutrophils $\left(0.7 \times 10^{6} \pm 0.07 \times 10^{6}\right)$.

Subset analysis also was performed in primary and secondary $H$. capsulatum to determine whether apoptosis involved $\mathrm{CD}^{+}$or

\section{Figure 2}

Phenotype of leukocytes isolated from lungs of mice infected with $H$. capsulatum for 7 days. Lung cells from mice with primary (A, C, and E) or secondary (B, D, and F) histoplasmosis were analyzed using allophycocyanin-labeled mAbs against the surface markers $\mathrm{CD} 3 \varepsilon$, Mac1, or Gr1 (A and B) or PE-labeled $m A b s$ against the surface markers CD4 and CD8 (C and D). Representative dot plots of at least 6 individual animals are shown. (E and $\mathbf{F}$ ) Leukocytes were isolated at 7,14 , and 21 days after primary $(E)$ and secondary $(F)$ infection with histoplasmosis. The percentage of macrophages was calculated by subtracting the number of $\mathrm{Gr} 1^{+}$cells from the number of Mac1 ${ }^{+}$cells. Data represent mean \pm SEM of 6 animals per group. Data from 1 of 2 experiments are shown.
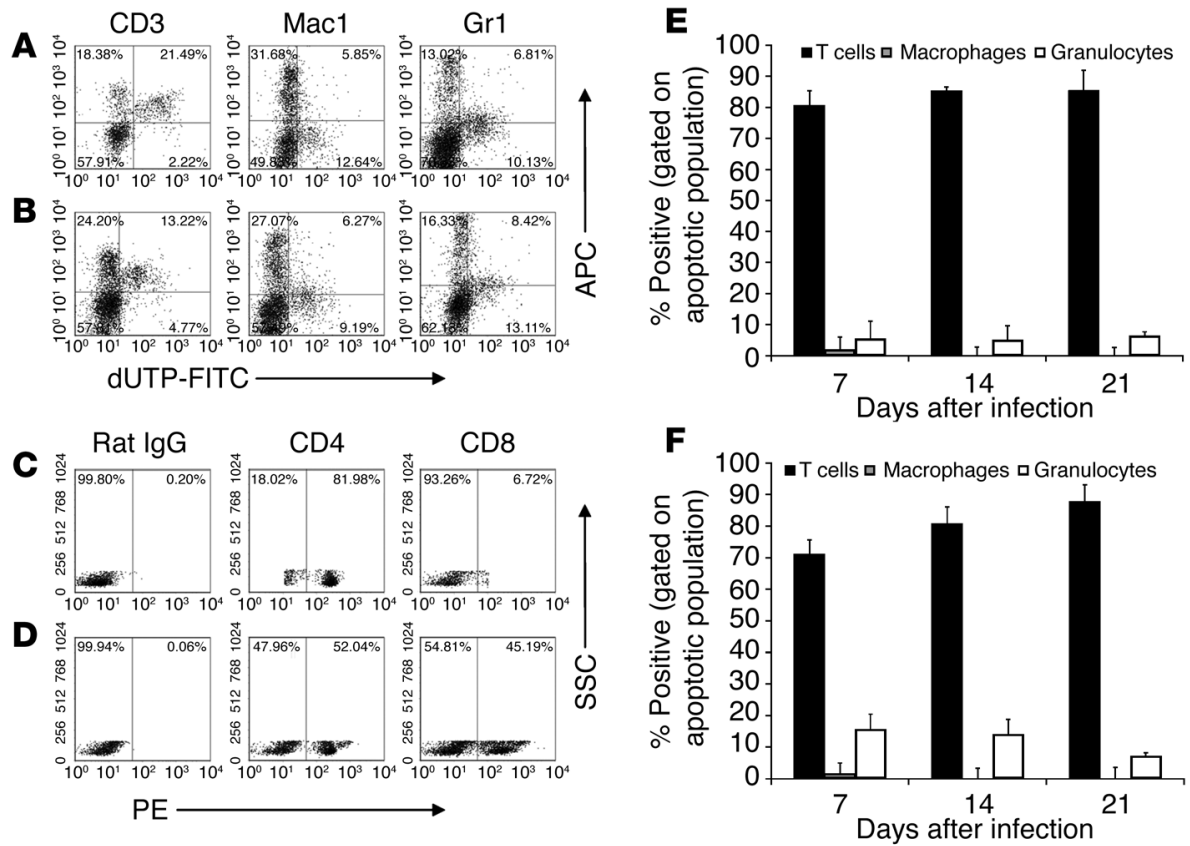
Table 1

Proportions of apoptotic memory/activated $\mathrm{CD}^{+}$cells during H. capsulatum infection

\begin{tabular}{lccc} 
& \multicolumn{3}{c}{ Mean $( \pm$ SEM) $\%$ of apoptotic CD3+ cells } \\
& $\begin{array}{c}\mathbf{7 ~ d} \\
\text { after infection }\end{array}$ & $\begin{array}{c}\mathbf{1 4} \mathbf{d} \\
\text { after infection }\end{array}$ & $\begin{array}{c}\mathbf{2 1} \mathbf{~ d} \\
\text { after infection }\end{array}$ \\
Primary $(n=6)$ & $83.1 \pm 2.1$ & $77.8 \pm 2.4$ & $84.8 \pm 1.7$ \\
Secondary $(n=6)$ & $86.2 \pm 3.4$ & $79.1 \pm 8.9$ & $83.2 \pm 5.2$ \\
\hline
\end{tabular}

AThe mean percentage of apoptotic cells from mice at day 0 prior to infection was less than $1 \%$.

$\mathrm{CD}^{+}$cells or both. Among $\mathrm{T}$ cells, the $\mathrm{CD}^{+}{ }^{+}$subset constituted the dominant population that was apoptotic in primary infection (Figure 2C). Between $70 \%$ and $90 \%$ of all T cells that were apoptotic were $\mathrm{CD}^{+}$. In secondary infection, there was a fairly equal distribution between $\mathrm{CD}^{+}$and $\mathrm{CD}^{+}$cells (Figure 2D). The proportion of apoptotic $\mathrm{T}$ cell subsets was similar to the percentages of these cell populations in the lungs.

We queried whether apoptotic T cells manifested a memory/ activated phenotype in both primary and secondary infection. To assess this phenotype, cells were incubated with mAbs against CD3, CD62L, and CD44. The cells that were CD3 ${ }^{+}, \mathrm{CD}_{62} \mathrm{~L}^{\mathrm{lo}}$, and CD $44^{\text {hi }}$ were defined as memory/activated cells. The proportion of $\mathrm{T}$ cells that bore this phenotype ranged from $77.8 \%$ to $86.2 \%$ (Table 1). The proportion of cells from mice on day 0 either prior to infection or reinfection that bore the memory/activated phenotype was less than $1 \%$.

Modulation of the apoptotic response by TNF- $\alpha$ or FasL. Neutralization of TNF- $\alpha$ abolishes the protective immune response to primary and secondary $H$. capsulatum and is accompanied by unrestricted growth of the fungus in the lungs of mice $(10,12,13,32)$. Moreover, the absence of either TNFR1 or TNFR2 is associated with failure to control $H$. capsulatum infection in mice (33). Hence, we sought to determine whether neutralization of this cytokine or the absence of either receptor altered the apoptotic response in the lungs at day 7 after infection. Administration of $\mathrm{mAb}$ against TNF- $\alpha$ to mice infected with $H$. capsulatum caused a marked and significant $(\mathrm{P}<0.01)$ reduction in the percentage of apoptotic cells within the lungs of mice in both primary and secondary infection (Figure 3, A and B). Neutralization of TNF- $\alpha$ in primary infection was associated with an exacerbation of infection at day 7 (Figure 3C).

In parallel, TNFR1 $1^{-/}$and TNFR2 $2^{-/-}$mice were infected with $H$. capsulatum, and at day 7 after infection, the lungs were examined for the percentage of apoptosis. The lungs of $H$. capsulatum-infected TNFR1-/- mice contained a much lower percentage of apoptotic cells $(P<0.01)$ than those of wild-type animals (Figure 3D). The percentage did not differ between wild-type and TNFR2 $2^{-/-}$mice $(P>0.05)$.

The apoptotic response also was assessed in gld/gld mice that possess a mutant FasL (34). The absence of this molecule was associated with a sharp decrease $(P<0.01)$ in the proportion of apoptotic cells at days 7 and 21 after infection in both primary and secondary histoplasmosis (Figure 4, A and E). The number of CFU in lungs of gld/gld mice was significantly greater $(P<0.01)$ than that in infected controls at day 7 , but not day 21, after infection in primary and secondary histoplasmosis (Figure 4, B and F).

Since TNF- $\alpha$ and FasL contributed to apoptosis in H. capsulatum-infected mice, we sought to determine whether neutralization of TNF- $\alpha$ would completely abolish this response in $\mathrm{gld} / \mathrm{gld}$ mice. mAbs against TNF- $\alpha$ or rat IgG were given to gld/gld mice and apoptosis assessed. Neutralization of this cytokine sharply reduced the apoptotic response in these mice in both primary and secondary infection (Figure $4, \mathrm{C}$ and $\mathrm{G}$ ). Treatment with $\mathrm{mAb}$ against TNF- $\alpha$ exacerbated infection on day 7 of primary and secondary histoplasmosis (Figure 4, D and H).

Does inhibition of apoptosis alter fungal burden in wild-type mice? The accumulated evidence indicated that the severity of infection was inversely correlated with the magnitude of the apoptotic response. To obtain direct evidence that this finding was pertinent to the infectious process, we challenged mice with H. capsulatum and treated them daily with either the general caspase inhibitor benzyloxycarbonyl-Asp(OMe)-fluoromethyl ketone (Boc-D-FMK) (35) or the control peptide, $N$-benzyloxycarbonyl-Phe-Asp-fluoromethyl ketone (Z-FA-FMK) (36). At day 7 of primary or secondary infection, mice were euthanized, and the apoptotic response and fungal burden were assessed. A separate group of animals was followed for survival. Boc-DFMK caused a pronounced inhibition of apoptosis, whereas the control peptide did not (Figure 5, A and D). The decrement in the apoptotic response was accompanied by a striking rise in the fungal burden $(P<0.01)$ in the lungs of animals on day 7 of infection (Figure 5, B and E). Furthermore, mice administered this caspase inhibitor died between days 12 and 14 after primary infection and days 15 and 20 after secondary infection (Figure 5, $\mathrm{C}$ and $\mathrm{F}$ ). The cause of death was overwhelming $H$. capsulatum infection, since the burden of infection at death exceeded $10^{8}$
A

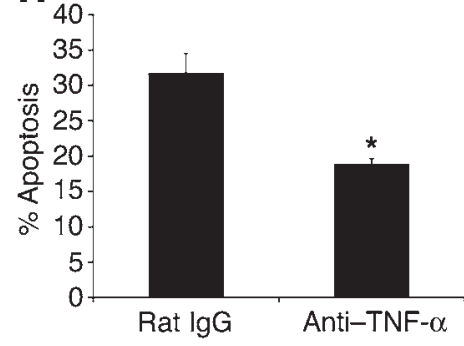

C

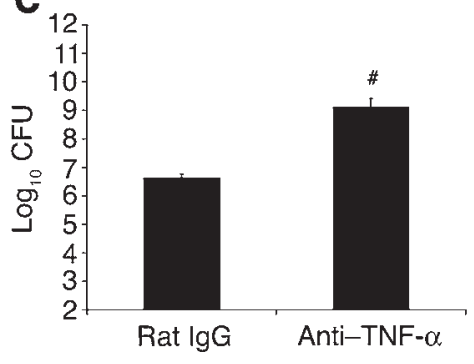

B
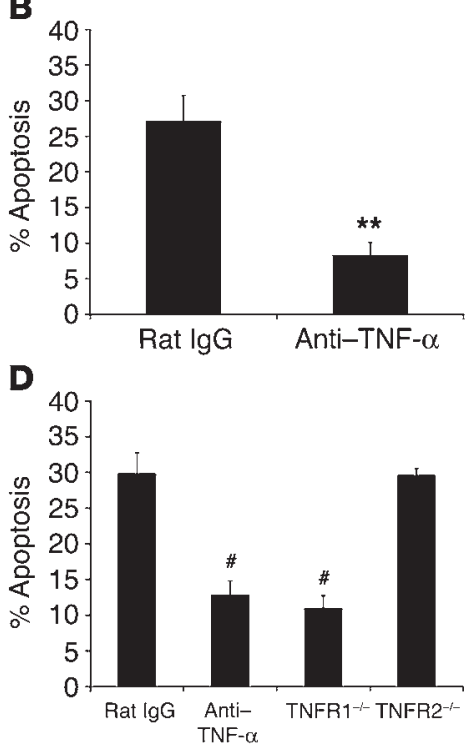

Figure 3

Effect of TNF- $\alpha$ on apoptosis in mice infected with $H$. capsulatum. On the day of infection, mice were treated with either rat IgG or mAb against TNF- $\alpha$ in primary (A) or secondary (B) histoplasmosis. (C) The fungal burden was assessed for mice receiving mAb against TNF- $\alpha$. (D) Wild-type C57BL/6 mice, TNFR1-1mice, or TNFR2 ${ }^{--}$mice were infected with $2 \times 10^{6}$ yeast cells i.n. Data represent the mean \pm SEM of 6 animals per group. ${ }^{*} P<0.05 ;{ }^{* *} P=0.01 ;{ }^{\#} P<0.001$. 
A

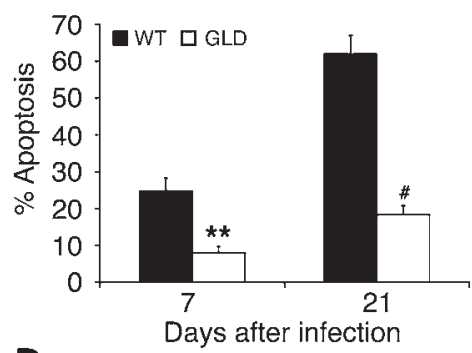

D

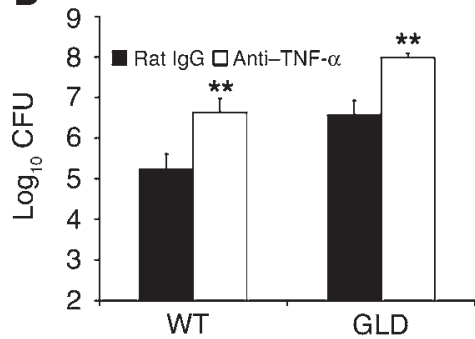

G

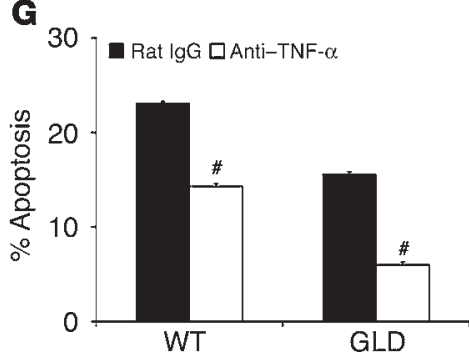

B

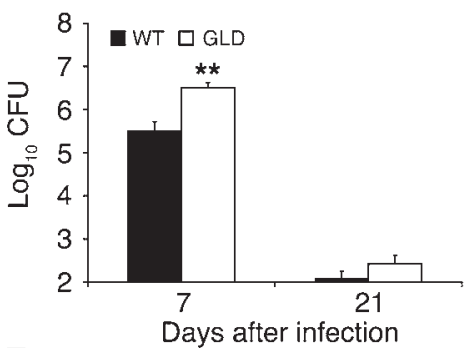

E

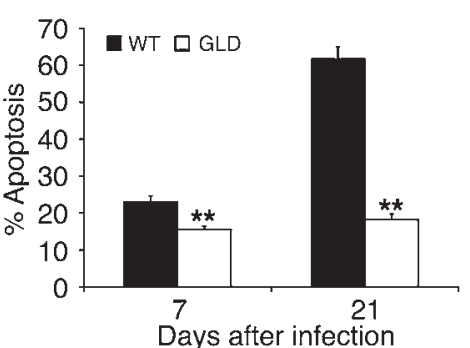

H

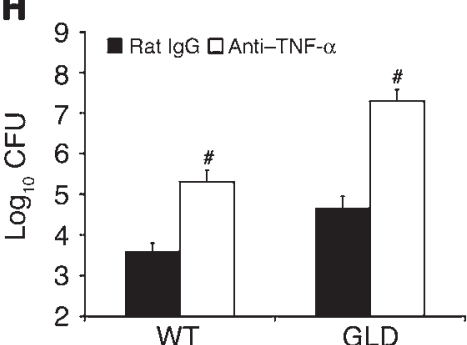

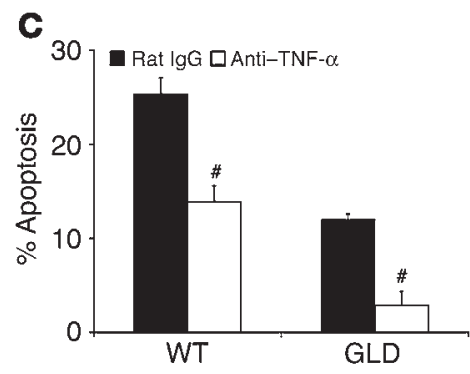

F

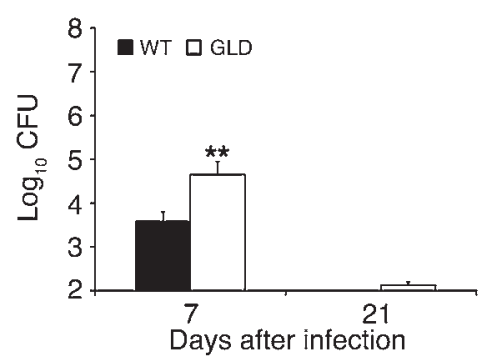

Figure 4

Apoptosis of lung leukocytes and fungal burden in g/d/gld (GLD) mice. In primary infection (A-D) and secondary infection (E-H), lung leukocytes were analyzed for apoptosis $(\mathbf{A}, \mathbf{C}, \mathbf{E}$, and $\mathbf{G})$ or fungal burden assessed $(\mathbf{B}, \mathbf{D}, \mathbf{F}$, and $\mathbf{H})$. (C, D, G, and $\mathbf{H})$ gld/gld mice were treated with either rat IgG or mAb to TNF- $\alpha$. Data represent mean \pm SEM of 6 animals per group. Data from 1 of 2 experiments are shown. ${ }^{* \star} P<0.01 ;{ }^{\#} P<0.001$.

CFU per lung. Treatment of uninfected mice with Boc-D-FMK for 21 days was not associated with death or illness in mice.

To determine whether the results with Boc-D-FMK could be generalized to those with another caspase inhibitor, we treated mice with Asp-Gln-Met-Asp-fluoromethyl ketone (z-DQMDFMK) or Z-FA-FMK and assessed apoptosis and fungal burden. Apoptosis of lung cells was decreased in mice treated with $z$-DQMD-FMK, and the fungal burden increased (Figure 5, $\mathrm{G}$ and $\mathrm{H})$. Thus, the antiapoptotic effect of caspase inhibition was inimical to host resistance.

Suramin and apoptosis. Suramin has been reported to be proapoptotic (37) and antiapoptotic (38). We postulated that if a proapoptotic dose of suramin was given to mice, it would decrease the fungal burden in $H$. capsulatum-infected mice. Prior to exploring the role of suramin, we examined whether this drug altered the viability of $H$. capsulatum. Mice were administered either $1 \mathrm{mg}$ i.p. of suramin or PBS at the time of infection with $2 \times 10^{6}$ yeast cells i.n. Recipients of $1 \mathrm{mg}$ suramin manifested an increase $(P<0.01)$ in the proportion of apoptotic leukocytes and a reduced $(P<0.001)$ fungal burden (Figure 6).

Cytokine analysis of lungs from mice given caspase inhibitor. The levels of cytokines in lung homogenates were analyzed in mice given Boc-D-FMK or Z-FA-FMK or in infected controls to determine whether inhibition of apoptosis was accompanied by alteration in those cytokines that are known to influence protective immunity. In primary and secondary infection, the lungs of mice $(n=5)$ given Boc-D-FMK contained significantly higher amounts of IFN- $\gamma$ and TNF- $\alpha$ compared with those of controls (Figure 7). The levels of IL-4 and IL-10 in lung homogenates also were strikingly higher $(P<0.01)$ in Boc-D-FMK-treated animals compared with controls.

In primary infection, the mean number $( \pm$ SEM $)$ of CD $3^{+}$IFN $-\gamma^{+}$ cells in lungs of Boc-D-FMK-treated mice $\left(2.60 \times 10^{4} \pm 0.03 \times 10^{4}\right)$ was similar to that of mice given Z-FA-FMK $\left(2.99 \times 10^{4} \pm 0.03 \times 10^{4}\right)$ or PBS $\left(2.49 \times 10^{4} \pm 0.07 \times 10^{4}\right)$. In secondary histoplasmosis, the mean number of $\mathrm{CD}^{+} \mathrm{IFN}-\gamma^{+}$cells in lungs of mice $(n=5)$ receiving Boc-D-FMK $\left(2.53 \times 10^{5} \pm 0.21 \times 10^{5}\right)$ was slightly less than $(P>0.05)$ than that found in lungs of mice given Z-FA-FMK $\left(2.61 \times 10^{5} \pm 0.26 \times 10^{5}\right)$ but slightly exceeded that in mice given PBS alone $\left(1.94 \times 10^{5} \pm 0.06 \times 10^{5}\right)$.

Treatment of $I \mathrm{~L}^{-4^{-/-}}$and $I L-10^{-/-}$mice with a caspase inbibitor. Since caspase inhibition of wild-type mice produced elevated levels of IL-4 and IL-10, which can modulate the course of infection with H. capsulatum, we determined whether either of these was responsible for the exacerbation of infection in mice given Boc-D-FMK. Groups of IL-4-/- and IL-10 $1 /$ - mice received PBS, Z-FA-FMK, or Boc-D-FMK, and apoptosis and fungal burden were assessed at 1 week of infection. Treatment with Boc-D-FMK inhibited apoptosis 
A

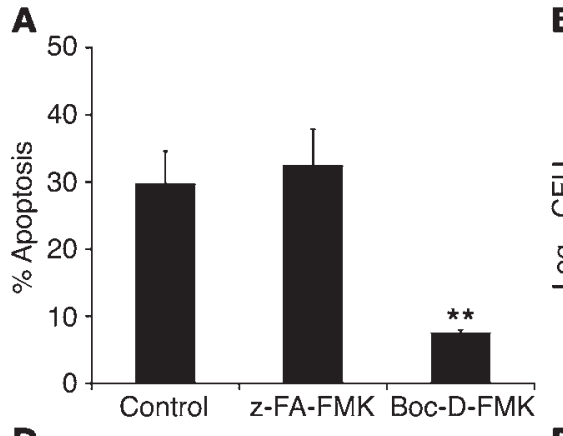

D
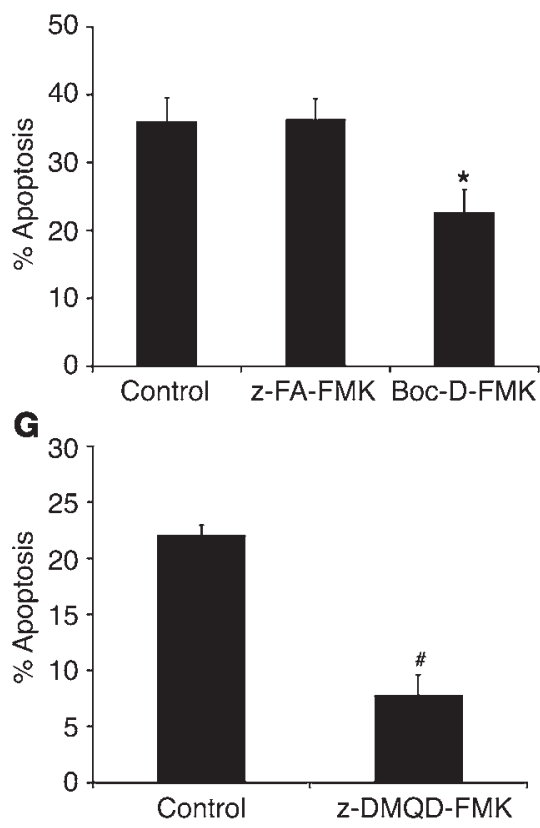

$\mathbf{B}$

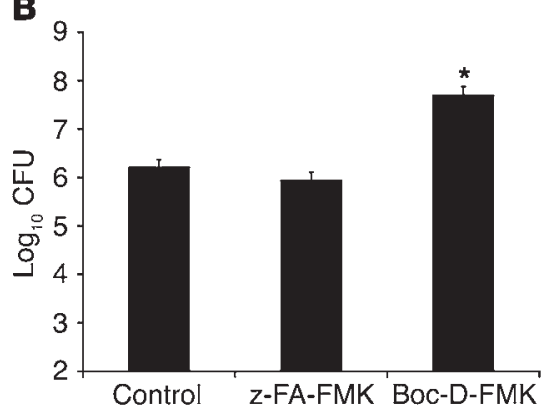

E

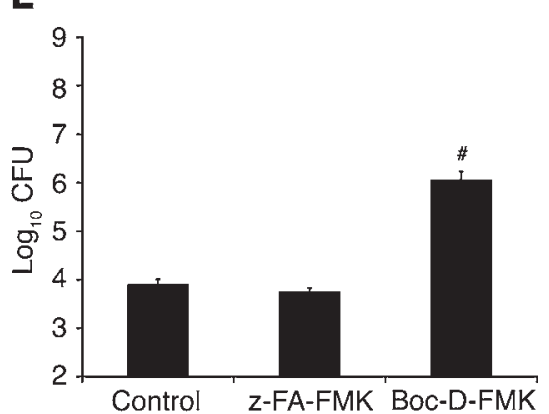

H

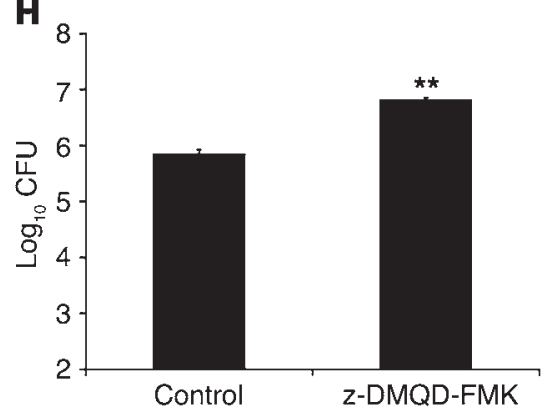

C

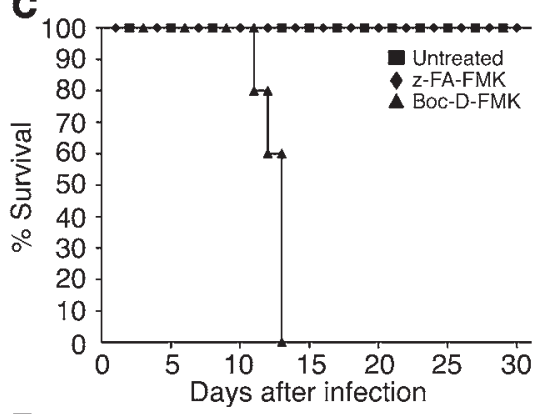

$\mathbf{F}$

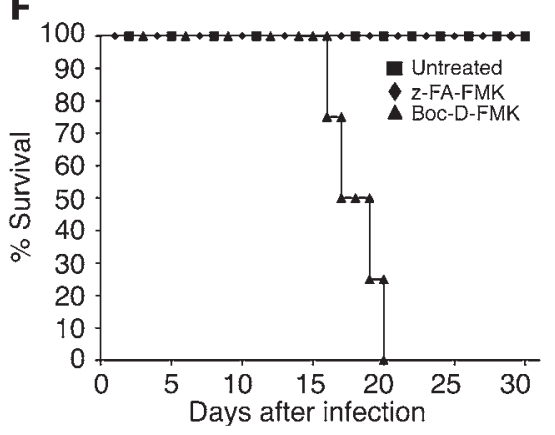

Figure 5

Effect of inhibitors of apoptosis on fungal burden in mice. Groups of mice were treated with either Boc-D-FMK $(\mathbf{A}-\mathbf{F})$ or with suramin $(\mathbf{G}$ and $\mathbf{H})$. Beginning the day of primary $(\mathbf{A}-\mathbf{C})$ or secondary (D-F) infection, mice were treated daily with HBSS, Boc-D-FMK, or Z-FA-FMK (10 $\mu \mathrm{mol} / \mathrm{kg})$. Lungs were harvested at 7 days after infection and were either assayed for apoptosis by flow cytometry (A and $\mathbf{D})$ or evaluated for fungal burden (B and $\mathbf{E})$. ( $\mathbf{C}$ and $\mathbf{F})$ Survival curves representing mice treated with either Boc-D-FMK or Z-FA-FMK daily until they succumbed to infection. Apoptosis $(\mathbf{G})$ and fungal burden $(\mathbf{H})$ were assessed in mice given z-DQMD-FMK. Data represent mean \pm SEM of 6 animals per group. Pooled results from 2-3 experiments are shown. ${ }^{*} P<0.050$; ${ }^{* *} P<0.010$; ${ }^{*} P<0.001$.

in both $\mathrm{IL}-10^{-/-}$and $\mathrm{IL}-4^{-/-}$mice (Figure 8 , A and C). The fungal burden in IL-4- - and IL-10-/- mice given Boc-D-FMK did not differ $(P>0.05)$ from that of recipients of PBS or Z-FA-FMK (Figure 8, $\mathrm{B}$ and $\mathrm{D})$. Thus, in the absence of either cytokine, Boc-D-FMK did suppress apoptosis but did not increase the severity of infection.

Effect of suramin or Boc-D-FMK on H. capsulatum growth. One concern with the above results is that suramin or Boc-D-FMK altered the growth of the fungus. H. capsulatum yeast cells exposed to suramin or Boc-D-FMK did not manifest altered growth as assessed by incorporation of $\left[{ }^{3} \mathrm{H}\right]$ leucine (Figure 9 , $\mathrm{A}$ and $\mathrm{B}$ ). Moreover, neither suramin nor Boc-D-FMK altered the morphology of the yeast cells (data not shown).

Several lower eukaryotes have been found to undergo apoptosis (39). A possible explanation for the unrestricted growth of yeast cells is that Boc-D-FMK blocked apoptosis of H. capsulatum within phagocytes, leading to enhanced intracellular growth. We tested the possibility that Boc-D-FMK would inhibit apoptosis in yeast cells induced by $\mathrm{H}_{2} \mathrm{O}_{2}$. Yeast cells were incubated with medium or with $30 \mu \mathrm{M} \mathrm{H}_{2} \mathrm{O}_{2}$ for 24 hours in the presence or absence or $50 \mu \mathrm{M}$ Boc-D-FMK or an equal concentration of Z-FA-FMK. The mean percentage $( \pm \mathrm{SEM} ; n=4)$ of apoptotic yeast cells in the absence of $\mathrm{H}_{2} \mathrm{O}_{2}$ was $3.2 \% \pm 0.2 \%$ and in its presence was $19.5 \% \pm 1.8 \%$ $(P<0.01)$. The percentage of apoptotic yeast cells coincubated with $\mathrm{H}_{2} \mathrm{O}_{2}$ and Z-FA-FMK was $19 \% \pm 2.2 \%$ and with Boc-D-FMK was $17.3 \% \pm 2.0 \%$. Neither of these values was significantly different $(P>0.05)$ from that of yeast cells incubated with $\mathrm{H}_{2} \mathrm{O}_{2}$ alone.

\section{Discussion}

In this study, we explored the potential influence of apoptosis on host resistance. We focused on apoptosis because of the prominent role of TNF- $\alpha$ as an inducer cell death $(28,40,41)$ and because apoptosis has been reported to modulate host defenses to microbes. Pathogens may trigger apoptosis of immunocompetent cells to avoid immune recognition $(22,42-45)$. Conversely, intracellular microbes such as Mycobacterium sp. may block apoptosis of macrophages to create a safe haven for replication (46-50). 


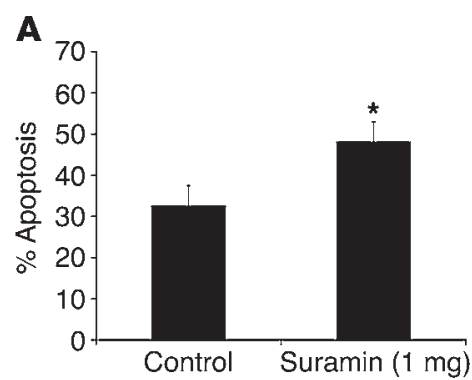

B

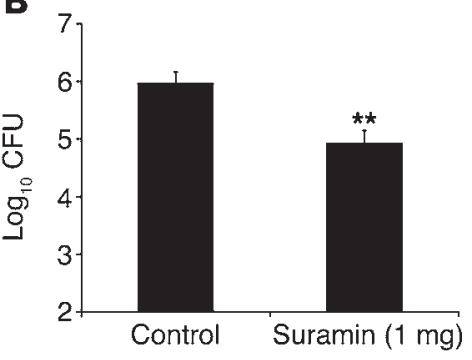

Figure 6

The proapoptotic effect of suramin decreases fungal burden. Mice were treated with $1 \mathrm{mg}$ of suramin i.p. or with HBSS alone at the time of infection. Lungs were harvested at 7 days postinfection and assayed for apoptosis by flow cytometry $(\mathbf{A})$ and fungal burden $(\mathbf{B}) .{ }^{* *} P<0.010$.

We demonstrated that lung leukocytes become apoptotic during the course of pulmonary infection with $H$. capsulatum. T cells bearing a memory/activated phenotype constituted the dominant population, whereas only a small percentage of neutrophils and a negligible fraction of macrophages were apoptotic. The latter finding is not entirely unexpected, since $H$. capsulatum inhibits apoptosis of macrophages (51). Another possibility for the paucity of apoptotic macrophages is that only a small fraction is infected and thus liable to undergo apoptosis. The data indicate that the magnitude of apoptotic response affects host resistance in both primary and secondary H. capsulatum inversely. Inhibition of apoptosis was associated with increased susceptibility to infection. These results strongly support the contention that apoptosis of $\mathrm{T}$ cells exerts a salutary effect on host defenses. It is unlikely that apoptotic neutrophils contributed to the findings, since they constituted such a small percentage of apoptotic cells and because in secondary $H$. capsulatum, their elimination does not impact the course of infection (10).

The deletion of $\mathrm{T}$ cells of the activated/memory phenotype can be interpreted in 2 ways. First, their removal is a means to contract the large pool of antigen-specific effector cells and limit the inflammatory response. The surviving activated/memory $\mathrm{T}$ cells may persist for prolonged periods and remain enabled to react to subsequent invasion by the offending pathogen (52). Another explanation arises from the knowledge that clearance of $H$. capsulatum is heavily dependent on T cells (2). In this scenario, the fungus induces apoptosis of $\mathrm{T}$ cells and thereby eliminates an essential regulatory element of host defenses.

The latter supposition is directly contrary to the observed outcomes in the current study. The rise in the percentage of apoptosis in lungs is inversely, rather than directly, correlated with fungal burden. In our model, the number of yeast cells in lungs peaks by day 7 and steadily declines thereafter. By day 21 , the number of CFU in lungs is most often 3 to $4 \log _{10}$ lower than at day $7(32,53)$. Similarly, in secondary infection, there is a sharp decline in the number of CFU in lungs, and by day 21 , the CFU are not detectable. The finding of an inverse relationship between fungal burden and apoptosis was extended to other models of $H$. capsulatum infection. Mice deficient in TNF- $\alpha$ or those with a mutation in the Fasl gene manifested increased susceptibility to infection and reduced apoptosis when compared with controls.

The absence of TNF- $\alpha$ or either of its 2 receptors, TNFR 1 or TNFR2, leads to the death of animals following i.n. challenge with $2 \times 10^{6}$ yeast cells, although TNFR1 $1^{-/}$mice are far more susceptible than those lacking TNFR2 $(6,33)$. Apoptosis of lung leukocytes was exclusively found in TNFR1 $1^{-/-}$mice. This finding correlates with the known existence of a death domain within the TNFR1 complex and its absence in TNFR2-/- mice (40), but apoptosis, especially of $\mathrm{CD}^{+}$cells, can be mediated through TNFR2 $(54,55)$. The failure of TNFR2 $2^{-/}$mice to control infection is associated with a profound deficiency of IFN- $\gamma(33)$. Although the evidence indicates that apoptosis is a crucial mediator of host resistance, it is not an exclusive one. The lack of modulation of apoptosis in TNFR2 $2^{-/}$mice may explain, in part, why they are less susceptible to infection than TNFR1 $1^{-/}$mice.

Both TNF- $\alpha$ and the Fas-FasL, mediators of the activationinduced cell death pathway, contributed to the apoptotic response in $H$. capsulatum infection. The fate of infection however, differed greatly between mice deficient in one or the other. Mice deficient in TNF- $\alpha$ usually succumb within 14 to 20 days after infection despite the route of the inoculum $(6,10,12)$. gld/gld mice, on the other hand, manifested an increased burden at day 7 and subsequently controlled $H$. capsulatum growth at day 21. Inhibition of apoptosis by either pathway is associated with an increased fungal burden during the phase of infection ( $\leq 7$ days) when innate immunity is dominant. The transition to adaptive immunity, which is vitally important for limiting $H$. capsulatum infection, fails to develop when endogenous TNF- $\alpha$ is deficient. The findings strongly suggest that the latter pathway is far more important in host control than the FasFasL interaction. In comparison, in the case of infection with another intracellular pathogen, Leishmania major, the opposite is true (56). The Fas pathway regulates parasite burden, whereas TNF- $\alpha$ modulates the inflammatory response.

To obtain direct proof regarding the influence of apoptosis on host resistance mechanisms, we administered a pan-caspase inhibitor to determine whether suppression of apoptosis would modulate the course of infection. Inhibition of apoptosis by BocD-FMK or Z-DQMD-FMK was accompanied by a profound exacerbation of infection, which led to the death of animals in both primary and secondary $H$. capsulatum infection. If inhibition of apoptosis worsened the severity of infection, we reasoned that enhancing apoptosis would ameliorate the fungal burden. Indeed, treatment with a proapoptotic amount of suramin decreased the $\mathrm{CFU}$ in lungs. The findings establish that activation of the apoptotic pathway in $H$. capsulatum infection serves as a positive regulator of protective immunity.

An explanation for the altered fungal growth in the presence of Boc-D-FMK was that the effect of the inhibitor was on the fungus rather than the host cells. Incubation of the inhibitor with H. capsulatum yeast cells exposed to a proapoptotic stimulus failed to inhibit the fungal apoptosis. This result is not surprising, since another caspase inhibitor failed to protect Aspergillus fumigatus 

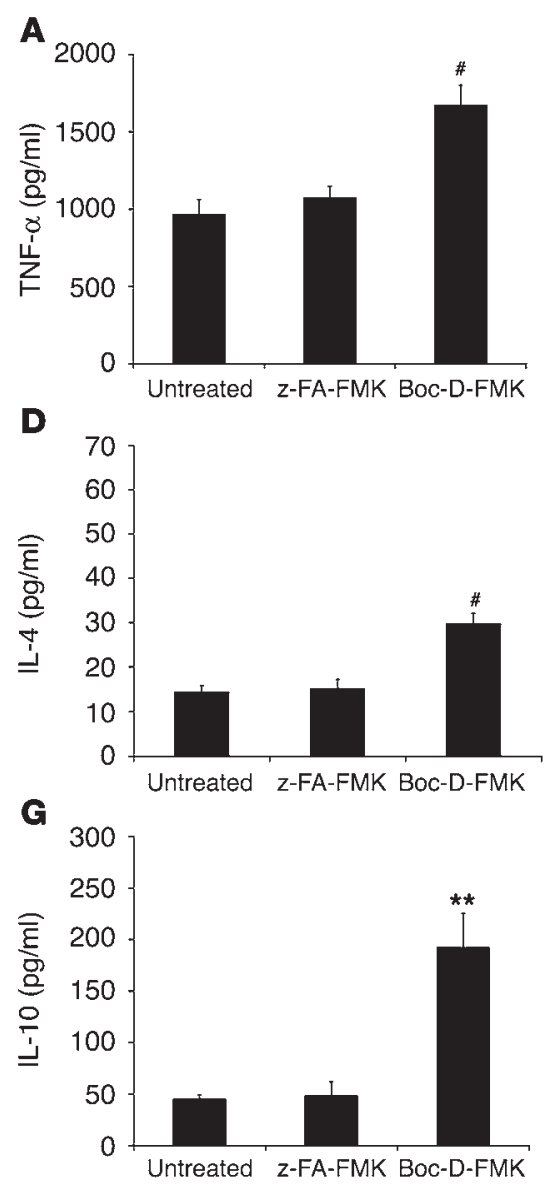
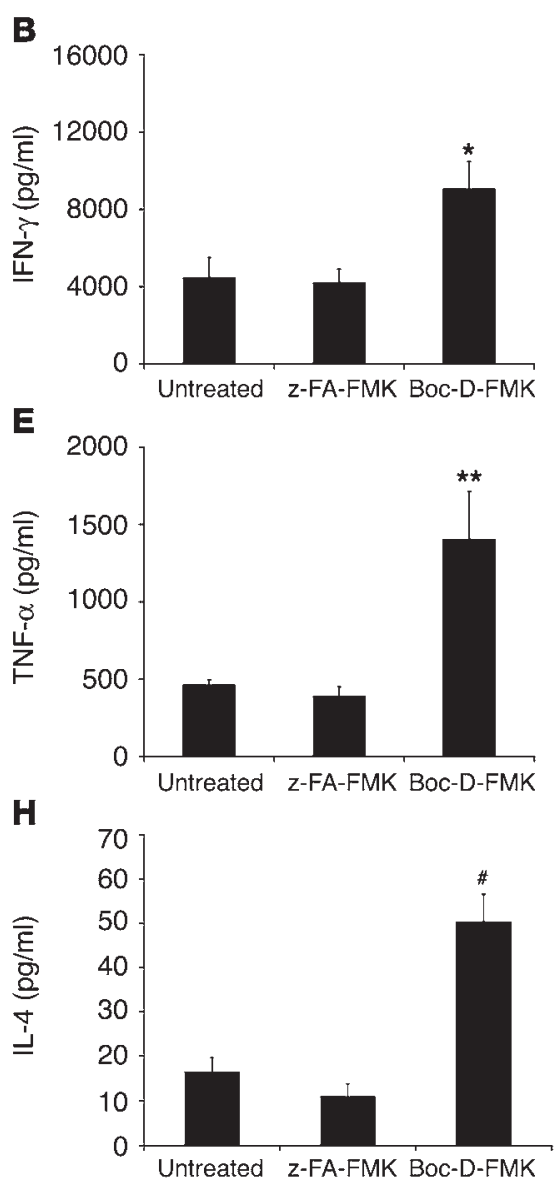
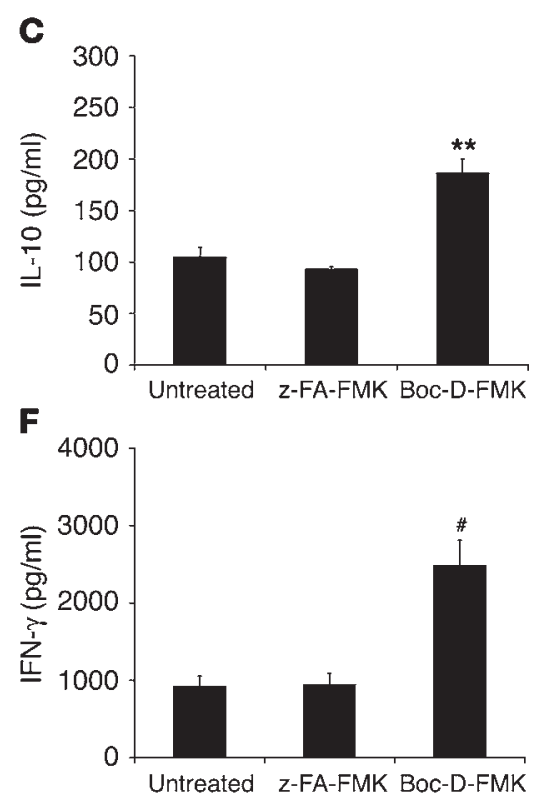

Figure 7

Cytokine profiles of $H$. capsulatum-infected mice treated with the apoptosis inhibitor Boc-D-FMK. (A-D) In primary infection, mice were infected with $2 \times 10^{6}$ yeast cells i.n. (E-H) In secondary infection mice were infected with $10^{4}$ yeast cells i.n. and 49 days later challenged with $2 \times 10^{6}$ $H$. capsulatum yeast cells i.n. Lungs were harvested at 7 days after infection, homogenized in HBSS, and assayed for TNF- $\alpha$ (A and E), IFN- $\gamma$ (B and F), IL-10 (C and G), and IL-4 (D and H). Data represent the mean \pm SEM of 6 animals per group. Data for 1 of 2 experiments are shown. ${ }^{\star} P<0.050 ;{ }^{\star \star} P<0.010$; ${ }^{\#} P<0.001$.

from apoptosis (57). The reason for this finding is unclear. Fungi appear to have metacaspases that are similar but not identical to mammalian caspases (58). Thus, the inhibitors of mammalian caspases may not recognize fungal metacaspases.

The results from our model stand in contrast to those of numerous studies in which lymphocyte apoptosis is associated with an inimical effect on the severity of infection. Transfer of apoptotic splenocytes or caspase inhibition of animals was associated with deleterious outcome in models of bacterial sepsis $(25,26,59,60)$. Furthermore, in type I IFN-deficient mice infected with Listeria monocytogenes, the course of infection is mitigated compared with that in controls (25). One of the underlying mechanisms explaining the salutary course in these mice was a reduction in lymphocyte apoptosis. In addition, TNFR1 $1^{-/}$mice infected with Yersinia enterocolitica manifest an enhanced clearance of bacteria in association with a decrease in apoptosis of $\mathrm{CD}^{+}$lymphocytes (61). The weight of evidence in bacterial disease processes suggests that there is a direct correlation between the magnitude of apoptosis and severity of infection. The reasons why apoptosis contributes to disease exacerbation in these models has not been delineated. One reason is that apoptotic $\mathrm{T}$ cells can release molecules such as TGF- $\beta$ that induce an immunosuppressive milieu and prohibit full expression of the protective immune response $(62,63)$.

One of the mechanisms by which $\mathrm{T}$ cell death causes exacerbation of $H$. capsulatum infection is in part linked to a shift in the immune response from a dominant Th1 to a Th2 phenotype. Production of IL-4 and IL-10 was significantly enhanced in recipients of Boc-D-FMK. In the absence of either of them, this compound inhibited apoptosis but not protective immunity. When IL-4 or IL-10 is deficient, there is dissociation between inhibition of apoptosis and fungal burden. IL-4 and IL-10 are known to impair the protective immune response to this fungus even when Th1 cytokines are present $(6-8,64,65)$. Hence, apoptosis may regulate the generation of a Th1 or Th2 response. The correlation between inhibition of apoptosis and an immune shift is not uniform in our model. In primary histoplasmosis, the antiapoptotic effect mediated by TNF- $\alpha$ neutralization is not accompanied by increased levels of IL-4 and IL-10 in lung homogenates (6). Although inhibition of apoptosis appears to exacerbate infection, the immune disturbances that lead to enhanced severity are not identical. 

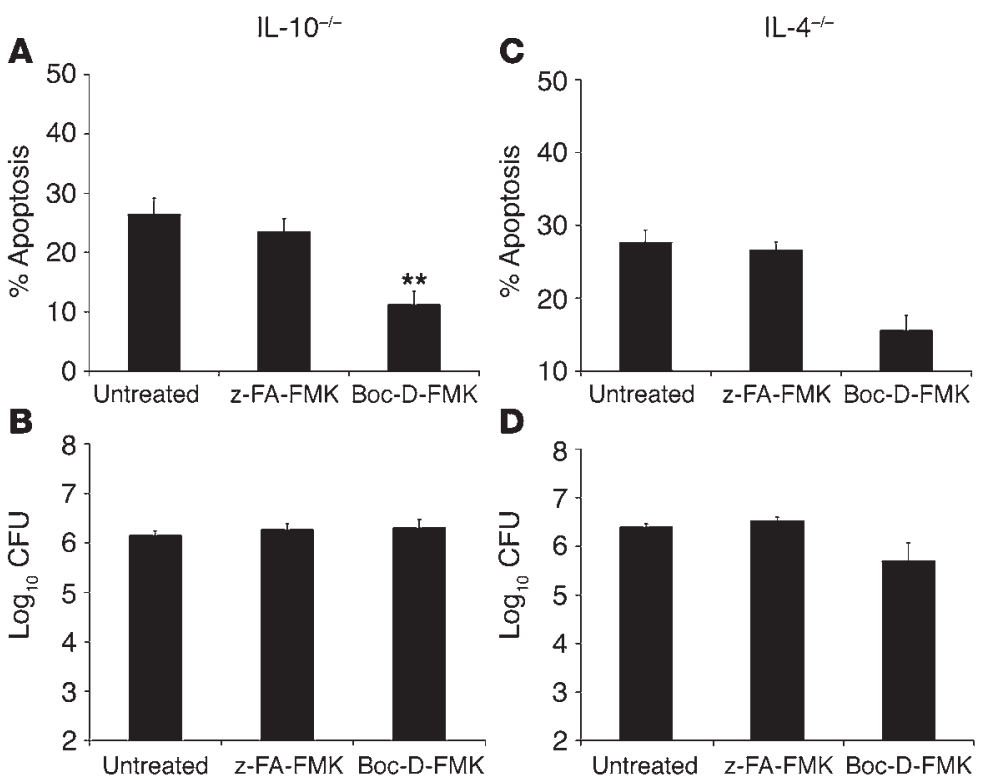

D

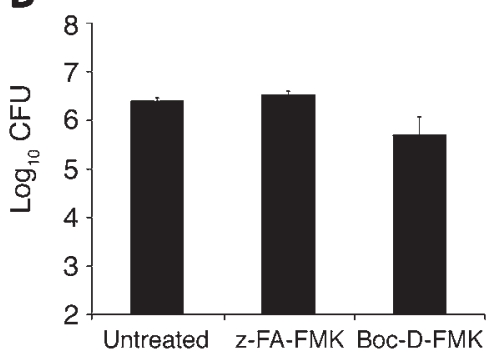

Figure 8

Apoptosis and fungal burden in IL-10-/- or IL-4-/- mice. Groups of IL-10-/- (A and B) or IL-4 $4^{-/-}(\mathbf{C}$ and $\mathbf{D})$ mice $(n=6)$ were infected with $2 \times 10^{6} \mathrm{H}$. capsulatum yeast cells and administered PBS, Z-FA-FMK, or Boc-D-FMK for 1week. Lungs were analyzed for the proportion of apoptotic cells ( $\mathbf{A}$ and $\mathbf{C})$ and fungal burden (B and $\mathbf{D})$. Data represent the mean \pm SEM. ${ }^{* *} P<0.010$.

In experimental $H$. capsulatum infection, we also found elevations in endogenous TNF- $\alpha$ and IFN- $\gamma$ in mice receiving Boc-D-FMK. The increase in IFN- $\gamma$ levels in lung homogenates was not a result of an elevated number of cytokine-producing cells, since these values were similar; rather the results suggest that each cell generated more IFN- $\gamma$. Moreover, the increased levels of both TNF- $\alpha$ and IFN- $\gamma$ were not sufficient to rescue mice in from the lethal effects of $H$. capsulatum. Thus, apoptosis may be important in preventing the induction of a dominant Th2 response in H. capsulatum.

The elevation in IL-4 and IL-10 associated with caspase inhibition may be a consequence of the host attempting to restrict the inflammatory response in the presence of excessive numbers of viable $\mathrm{T}$ cells. This counteraction has a negative impact on the protective immune response. The unanticipated finding of a decrement in $\mathrm{T}$ cell apoptosis and increased burden of infection has been demonstrated in experimental trypanosomiasis. FasL-deficient mice exhibit diminished apoptosis and higher burdens of parasitemia. In that model system, susceptibility to infection in FasL-deficient mice is accompanied by increases in levels of both IL-4 and IL-10 $(66,67)$. The authors ascribe their findings to a Fas-FasL interaction, but our data suggest that apoptosis-mediated regulation of a Th1 or Th2 response may be downstream of Fas engagement, that is, at the level of caspases. Furthermore, modulation of caspase activity has been shown to modify production of cytokines, although the mechanisms

\section{Figure 9}

$\left[{ }^{3} \mathrm{H}\right]$ leucine incorporation by $\mathrm{H}$. capsulatum yeast cells in the presence or absence of suramin (A) or Boc-D-FMK (B). The data are expressed as percent of control. For suramin, the control was yeast cells incubated with PBS. For Boc-D-FMK, the control was yeast cells incubated with Z-FA-FMK. Data represent the mean \pm SEM of at least 5 experiments. Yeast cells were cultured in triplicate for each concentration of agent. are not known (68). Thus, according to one model for our findings, caspase inhibition induces the production of IL- 4 and IL- 10 by T cells that are not eliminated by apoptosis and thus can produce a sustained impairment of the host immune response. An alternative but not mutually exclusive interpretation is that caspase inhibitors modulate Th2 cytokine production. Thus, the caspase inhibitor Z-VAD-FMK augments IL-4 production by primary but not Th2-committed T cells (69). In this regard, levels of IFN- $\gamma$, IL-4, and IL-10 in lung homogenates of uninfected mice administered Boc-D-FMK or suramin for 7 days did not differ from those of mice given either Z-FA-FMK or PBS (data not shown).

One of the concerns raised in using caspase inhibitors is that they express other biological activities. Several have been shown to suppress cathepsin activity, although this property has been identified principally, if not exclusively, in vitro (70). Boc-D-FMK is not known to inhibit cathepsins, but the control peptide, Z-FA-FMK, inhibits cathepsins B and L (36). The role of cathepsins in host defenses to this fungus is poorly understood. Cathepsin $\mathrm{G}$ inhibits, but does not kill, H. capsulatum yeast cells (71). Thus, it seems unlikely that Boc-D-FMK subverts protective immunity by a direct alteration of cathepsin activity.

In summary, we have demonstrated that $H$. capsulatum induces apoptosis in the lungs of mice. T cells were the dominant apoptotic population. Inhibition of apoptosis was associated with an increased fungal burden in mice treated with $\mathrm{mAb}$ against TNF- $\alpha$, in $g l d /$ gld mice, and in animals given caspase inhibitors. Taken together, the results clearly demonstrate that the magnitude of apoptosis can influence host resistance mechanisms to this fungus. A decrement in apoptosis of $\mathrm{T}$ cells blunts clearance of $H$. capsulatum. These results conflict with the prevailing idea that in infectious diseases, apoptosis is inimical for host resistance mechanisms. The findings raise the possibility that apoptosis not only influences susceptibility to infection but also serves as a marker of its severity.
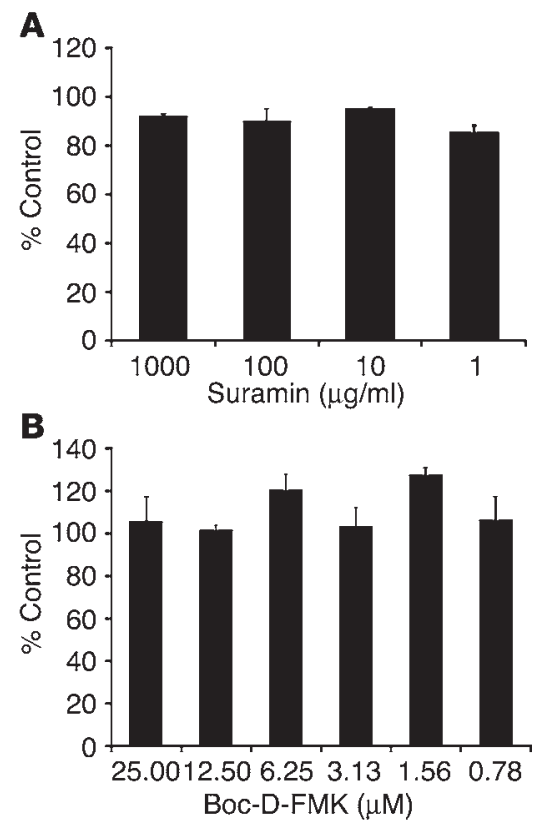


\section{Methods}

Mice. C57BL/6 mice, TNFR1 $1^{--}$, TNFR2 $2^{-/-}$, IL-10 $10^{-/}$, IL-4-/, and $g l d / g l d$ mice were purchased from the Jackson Laboratory. Athymic nude mice, which were used to generate ascites, were purchased from the National Cancer Institute. Animals were housed in isolator cages and were maintained by the Department of Laboratory Animal Medicine, University of Cincinnati, which is accredited by the Association for Assessment and Accreditation of Laboratory Animal Care. All animal experiments were performed in accordance with the Animal Welfare Act guidelines of the NIH, and all protocols were approved by the Institutional Animal Care and Use Committee of the University of Cincinnati.

Preparation of H. capsulatum and infection of mice. H. capsulatum yeast (strain G217B) was prepared as described previously (2). To produce infection in naive mice, animals were inoculated i.n. with $2 \times 10^{6} \mathrm{H}$. capsulatum yeast cells in a $30-\mu \mathrm{l}$ volume of HBSS. For secondary histoplasmosis, mice were initially inoculated with $10^{4}$ yeast i.n. in a volume of $30 \mu \mathrm{l}$. Six to 8 weeks later, previously exposed animals were rechallenged i.n. with $2 \times 10^{6}$ yeast cells.

Organ culture for $H$. capsulatum. Recovery of $H$. capsulatum was performed as described elsewhere (2). Fungal burden was expressed as mean CFU per whole organ \pm SEM. The limit of detection was $10^{2} \mathrm{CFU}$.

$m A b$. Rat anti-mouse TNF- $\alpha$ (from cell line XT-22.1) was purified from ascites. The cell line was obtained from J. Abrams (DNAX Research Institute, Palo Alto, California, USA). The concentration of rat IgG in ascites was assessed by ELISA after protein $G$ purification and the amount calculated by linear regression from a rat IgG (Organon Teknika) standard curve.

Treatment of mice with neutralizing $m A b$ against TNF- $\alpha$. Mice were injected i.p. with $1 \mathrm{mg}$ of $\mathrm{mAb}$ against TNF- $\alpha$ at the time of challenge with H. capsulatum and each week thereafter. Previous studies have established that this amount inhibits the biological activity of TNF- $\alpha$ for up to 7 days (6). Control animals received an equal amount of rat IgG concomitantly.

Isolation of lung leukocytes. Lungs were teased apart with the frosted ends of 2 glass slides in $10 \mathrm{ml}$ of HBSS. The solution was filtered through $60 \mu \mathrm{m}$ nylon mesh (Spectrum Laboratories Inc.) and washed 3 times with HBSS. Leukocytes were isolated by separation on a 40-70\% Percoll (Pharmacia) gradient.

Flow cytometry. All surface staining was performed before analysis of apoptosis. To determine the phenotype of apoptotic cells, lung leukocytes were adjusted to a concentration of $2 \times 10^{6}$ cells $/ 200 \mu \mathrm{l}$ of staining buffer (PBS containing $2 \%$ BSA and $0.02 \%$ sodium azide) and incubated with $0.5 \mu \mathrm{g}$ of one of the following allophycocyanin-labeled mAbs (BD Biosciences) against: $\mathrm{CD} 3 \varepsilon$ (clone 145-2C11), CD4 (clone GK1.5), CD8 (clone 2.43), Ly-6G (Gr1; clone RB6-8C5), CD11b (Mac1; clone M1/70). The percentage of macrophages was calculated by subtracting the percentage of cells that bore Mac-1 from those that expressed Gr1. To measure the expression of intracellular IFN- $\gamma$, surface-stained cells were washed several times in Perm/Wash Buffer (BD Biosciences), fixed and permeabilized with BD Cytofix/Cytoperm (BD Biosciences), and stained with IFN- $\gamma-\mathrm{PE}$ (clone $\mathrm{XMG} 1.2 ; 2.5 \mu \mathrm{g} / 10^{6}$ cells). The cells were washed in Perm/Wash buffer, and fluorescence was measured.

To determine memory phenotype, cells were stained with the following $\mathrm{mAbs}$ (BD Biosciences) against: $\mathrm{CD} 3 \varepsilon$-peridinin chlorophyll protein (clone 145-2C11), CD44-PE (Ly-24; clone Pgp-1), and CD62L-allophycocyanin (L-selectin; clone MEL-14). Staining with isotype-matched rat IgG or hamster IgG $\mathrm{mAb}$ was performed in parallel. The samples were washed and fixed in $2 \%$ paraformaldehyde at $4^{\circ} \mathrm{C}$. To determine whether cells were apoptotic, the TUNEL assay was used to add dUTP-FITC to ends of DNA double-strand breaks (In Situ Cell Death Detection Kit; Roche Diagnostic Corp.). The kit was used according to the manufacturer's instructions. In brief, cells were incubated in permeabilization solution $(0.1 \%$ sodium citrate, $0.1 \%$ Triton X-100) for 2 minutes at room temperature and washed in PBS. The cells were then incubated in the TUNEL reaction mixture (labeling solution without addition of TdT enzyme was used as a negative control) for 1 hour at $37^{\circ} \mathrm{C}$ in a humidified chamber. Cells were washed and resuspended in PBS, and fluorescence intensity assessed using a FACSCalibur flow cytometer (BD Biosciences). In preliminary experiments, cells were stained with proliferating cell nuclear antigen (PCNA) to determine whether the TUNEL-positive cells actually represented apoptotic cells. The proportion of TUNEL-positive cells that were PCNA positive was negligible.

To determine the intracellular IFN- $\gamma$ expression, cells were stained with allophycocyanin-conjugated $\mathrm{mAb}$ against $\mathrm{CD} 3 \varepsilon$, which was followed by permeabilization of cells and staining with PE-conjugated IFN- $\gamma$ (BD Pharmingen) as described previously (72).

Cytokine analysis of lung homogenates. Lung homogenates were prepared as described previously (6), and levels of IL-4, IL-10, IFN- $\gamma$, and TNF- $\alpha$ were quantified by ELISA.

Inhibition of apoptosis in vivo. The irreversible, pan-caspase inhibitor BocD-FMK (Sigma-Aldrich), the caspase inhibitor z-DQMD-FMK (Calbiochem), and the control peptide, Z-FA-FMK (Sigma-Aldrich), were dissolved in DMSO and administered to mice i.p. $(10 \mu \mathrm{mol} / \mathrm{kg})$. Mice were treated daily, beginning the day of infection, until the animals were sacrificed. The control, Z-FA-FMK, is a cathepsin inhibitor. In preliminary studies, we demonstrated that the infection in mice given DMSO alone was no different from that in mice given control Z-FA-FMK or given PBS. Suramin was purchased from Sigma-Aldrich and dissolved in PBS. Mice were given a single injection at the time of infection.

In vitro assays of $H$. capsulatum growth. Analysis of the in vitro growth of yeast cells in the presence of suramin or Boc-D-FMK was assessed by $\left[{ }^{3} \mathrm{H}\right]$ leucine incorporation as previously reported, and this assay has a direct correlation with CFU (73). Briefly, $5 \times 10^{4}$ yeast cells were suspended in $190 \mu \mathrm{l}$ of Ham's F12 medium, added to each well of a microtiter plate, and mixed with DMSO, Z-FA-FMK, or Boc-D-FMK. Yeast cells were cultured in triplicate with each concentration of agent and were grown at $37^{\circ} \mathrm{C}$ in $5 \% \mathrm{CO}_{2}$. After 24 hours of incubation, the plates were centrifuged at $1,000 \mathrm{~g}$ and the supernatant gently removed. Fifty microliters of $\left[{ }^{3} \mathrm{H}\right]$ leucine $(1 \mu \mathrm{Ci})$ (specific activity, $153 \mathrm{Ci} / \mathrm{mmol}$; New England Nuclear) and $5 \mu \mathrm{l}$ of $\times 10$ yeast nitrogen broth was added to each well. After an additional 24 hours at $37^{\circ} \mathrm{C}$ in $5 \% \mathrm{CO}_{2}, 50 \mu$ of L-leucine and $50 \mu \mathrm{l}$ of sodium hypochlorite were dispensed into each well. The contents were harvested onto glass fiber filters and counts per minute determined by scintillation counting.

Induction of apoptosis in H. capsulatum yeast cells. Log-phase yeast cells $\left(2 \times 10^{6}\right)$ were incubated in 24-well plates in the presence or absence of 20 or $40 \mu \mathrm{M}$ $\mathrm{H}_{2} \mathrm{O}_{2}$ for 24 at $37^{\circ} \mathrm{C}$ in $5 \% \mathrm{CO}_{2}$. Yeast cells were harvested and stained using the TUNEL kit for detection of apoptosis.

Statistical analyses. ANOVA was used to compare groups. Log-rank sum test was used to analyze survival. $P<0.05$ was considered statistically significant.

\section{Acknowledgments}

The authors would like to thank David Hildeman for several constructive criticisms and reviewing the manuscript. This work was supported by a Merit Review Grant from the Department of Veterans Affairs and by NIH grants AI-34361 and AI-42747.

Received for publication April 15, 2005, and accepted in revised form June 28, 2005.

Address correspondence to: George S. Deepe Jr., Division of Infectious Diseases, Department of Medicine, University of Cincinnati College of Medicine, 231 Albert Sabin Way, Cincinnati, Ohio 45267-0560, USA. Phone: (513) 558-4704, Fax: (513) 558-2089; E-mail: george.deepe@uc.edu. 
1. Deepe, G.S., Jr. 2000. Histoplasma capsulatum. In Principles and practice of infectious diseases. 5 th edition. G.L. Mandell, J.E. Bennett, and R. Dolin, editors. Churchill Livingstone. Philadelphia, Pennsylvania, USA. 2718-2732

2. Allendorfer, R., Brunner, G.D., and Deepe, G.S., Jr. 1999. Complex requirements for nascent and memory immunity in pulmonary histoplasmosis. J. Immunol. 162:7389-7396.

3. Deepe, G.S., Jr. 1994. Role of $\mathrm{CD}^{+} \mathrm{T}$ cells in host resistance to systemic infection with Histoplasma capsulatum in mice. J. Immunol. 152:3491-3500.

4. Gomez, A.M., Bullock, W.E., Taylor, C.L., and Deepe, G.S., Jr. 1988. Role of L3T4+ T cells in host defense against Histoplasma capsulatum. Infect. Immun. 56:1685-1691.

5. Zhou, P., and Seder, R.A. 1998. CD40 ligand is not essential for induction of type 1 cytokine responses or protective immunity after primary or secondary infection with Histoplasma capsulatum. J. Exp. Med. 187:1315-1324.

6. Allendoerfer, R., and Deepe, G.S., Jr. 1998. Blockade of endogenous TNF-alpha exacerbates primary and secondary pulmonary histoplasmosis by differential mechanisms. J. Immunol. 160:6072-6082.

7. Allendoerfer, R., Biovin, G.P., and Deepe, G.S., Jr. 1997. Modulation of immune responses in murine pulmonary histoplasmosis. J. Infect. Dis. 175:905-914.

8. Zhou, P., et al. 1995. IL-12 prevents mortality in mice infected with Histoplasma capsulatum through induction of IFN-gamma. J. Immunol. 155:785-795.

9. Zhou, P., Sieve, M.C., Tewari, R.P., and Seder, R.A 1997. Interleukin-12 modulates the protective immune response in SCID mice infected with Histoplasma capsulatum. Infect. Immun. 65:936-942.

10. Zhou, P., Miller, G., and Seder, R.A. 1998. Factors involved in regulating primary and secondary immunity to infection with Histoplasma capsulatum: TNF-alpha plays a critical role in maintaining secondary immunity in the absence of IFN-gamma. J. Immunol. 160:1359-1368.

11. Deepe, G.S., Jr., Gibbons, R., and Woodward, E. 1999. Neutralization of endogenous granulocytemacrophage colony-stimulating factor subverts the protective immune response to Histoplasma capsulatum. J. Immunol. 163:4985-4993.

12. Smith, J.G., Magee, D.M., Williams, D.M., and Graybill, J.R. 1990. Tumor necrosis factor-alpha plays a role in host defense against Histoplasma cap sulatum. J. Infect. Dis. 162:1349-1353.

13. Wu-Hsieh, B.A., Lee, G.S., Franco, M., and Hofman, F.M. 1992. Early activation of splenic macrophages by tumor necrosis factor alpha is important in determining the outcome of experimental histoplasmosis in mice. Infect. Immun. 60:4230-4238.

14. Allendoerfer, R., and Deepe, G.S., Jr. 1997. Intrapulmonary response to Histoplasma capsulatum in gamma interferon knockout mice. Infect. Immun. 65:2564-2569.

15. Wu-Hsieh, B. 1989. Relative susceptibilities of inbred mouse strains $\mathrm{C} 57 \mathrm{BL} / 6$ and $\mathrm{A} / \mathrm{J}$ to infection with Histoplasma capsulatum. Infect. Immun. 57:3788-3792.

16. Lee, J.H., et al. 2002. Life-threatening histoplasmosis complicating immunotherapy with tumor necrosis factor $\alpha$ antagonists infliximab and etanercept. Arthritis Rheum. 46:2565-2570.

17. Wood, K.L., et al. 2003. Histoplasmosis after treatment with anti-tumor necrosis factor- $\alpha$ therapy. Am. J. Respir. Crit. Care Med. 167:1279-1282.

18. Badovinac, V.P., Porter, B.B., and Harty, J.T. 2002. Programmed contraction of $\mathrm{CD}^{+} \mathrm{T}$ cells after infection. Nat. Immunol. 3:619-626.

19. Gavrilescu, L.C., and Denkers, E.Y. 2003. Apoptosis and the balance of homeostatic and pathologic responses to protozoan infection. Infect. Immun.
71:6109-6115

20. Nagata, S. 1997. Apoptosis by death factor. Cell. 88:355-365.

21. Thompson, C.B. 1995. Apoptosis in the pathogenesis and treatment of disease. Science. 267:1456-1462.

22. Weinrauch, Y., and Zychlinsky, A. 1999. The induction of apoptosis by bacterial pathogens. Annu. Rev. Microbiol. 53:155-187.

23. Cohen, J.J., Duke, R.C., Fadok, V.A., and Sellins, K.S. 1992. Apoptosis and programmed cell death in immunity. Annu. Rev. Immunol. 10:267-293.

24. Steller, H. 1995. Mechanisms and genes of cellular suicide. Science. 267:1445-1449.

25. Carrero, J.A., Calderon, B., and Unanue, E.R. 2004. Type I interferon sensitizes lymphocytes to apoptosis and reduces resistance to listeria infection. J. Exp. Med. 200:535-540.

26. Hotchkiss, R.S., et al. 2000. Caspase inhibitors improve survival in sepsis: a critical role of the lymphocyte. Nat. Immunol. 1:496-501.

27. Beg, A.A., and Baltimore, D. 1996. An essential role for NF-kappaB in preventing TNF-alpha-induced cell death. Science. 274:782-784

28. Hu, W.H., Johnson, H., and Shu, H.B. 1999. Tumor necrosis factor-related apoptosis-inducing ligand receptors signal NF-kappaB and JNK activation and apoptosis through distinct pathways. J. Biol. Chem. 274:30603-30610.

29. De Nadai, C., et al. 2000. Nitric oxide inhibits tumor necrosis factor- $\alpha$-induced apoptosis by reducing the generation of ceramide. Proc. Natl. Acad. Sci. U. S. A. 97:5480-5485.

30. Gomez, F.J., Gomez, A.M., and Deepe, G.S., Jr. 1991. Protective efficacy of a 62-kilodalton antigen, HIS-62, from the cell wall and cell membrane of Histoplasma capsulatum yeast cells. Infect. Immun. 59:4459-4464

31. Newman, S.L., Gootee, L., Brunner, G., and Deepe, G.S., Jr. 1994. Chloroquine induces human macrophage killing of Histoplasma capsulatum by limiting the availability of intracellular iron and is therapeutic in a murine model of histoplasmosis. J. Clin. Invest. 93:1422-1429.

32. Gomez, F.J., Cain, J.A., Gibbons, R., Allendoerfer, R., and Deepe, G.S., Jr. 1998. Vbeta4(+) T cells promote clearance of infection in murine pulmonary histoplasmosis. J. Clin. Invest. 102:984-995.

33. Allendoerfer, R., and Deepe, G.S., Jr. 2000. Regulation of infection with Histoplasma capsulatum by TNFR1 and -2. J. Immunol. 165:2657-2664.

34. Griffith, T.S., Brunner, T., Fletcher, S.M., Green, D.R., and Ferguson, T.A. 1995. Fas ligand-induced apoptosis as a mechanism of immune privilege. Science. 270:1189-1192.

35. Bidere, N., et al. 2002. Selective inhibition of dipeptidyl peptidase I, not caspases, prevents the partial processing of procaspase- 3 in CD3-activated human $\mathrm{CD}^{+} \mathrm{T}$ lymphocytes. J. Biol. Chem. 277:32339-32347.

36. Schotte, P., Schauvliege, R., Janssens, S., and Beyaert, R. 2001. The cathepsin B inhibitor z-FA.fmk inhibits cytokine production in macrophages stimulated by lipopolysaccharide. J. Biol. Chem. 276:21153-21157.

37. Kuyu, H., Lee, W.R., Bare, R., Hall, M.C., and Torti, F.M. 1999. Recent advances in the treatment of prostate cancer. Ann. Oncol. 10:891-898.

38. Eichhorst, S.T., et al. 2004. Suramin inhibits death receptor-induced apoptosis in vitro and fulminant apoptotic liver damage in mice. Nat. Med 10:602-609.

39. Madeo, F., et al. 2004. Apoptosis in yeast. Curr. Opin. Microbiol. 7:655-660

40. Aggarwal, B.B. 2003. Signalling pathways of the TNF superfamily: a double-edged sword. Nat. Rev. Immunol. 3:745-756.

41. Wallach, D., et al. 1999. Tumor necrosis factor receptor and Fas signaling mechanisms. Annu. Rev. Immunol. 17:331-367.

42. Das, G., Vohra, H., Saha, B., Agrewala, J.N., and Mishra, G.C. 1999. Apoptosis of Th1-like cells in experimental tuberculosis (TB). Clin. Exp. Immunol. 115:324-328

43. Dalton, D.K., Haynes, L., Chu, C.Q., Swain, S.L., and Wittmer, S. 2000. Interferon $\gamma$ eliminates responding $\mathrm{CD} 4 \mathrm{~T}$ cells during mycobacterial infection by inducing apoptosis of activated CD4 T cells. J. Exp. Med. 192:117-122.

44. Mannering, S.I., Zhong, J., and Cheers, C. 2002. $\mathrm{T}$-cell activation, proliferation and apoptosis in primary Listeria monocytogenes infection. Immunology. 106:87-95.

45. Hotchkiss, R.S., et al. 2001. Sepsis-induced apoptosis causes progressive profound depletion of $B$ and $\mathrm{CD} 4{ }^{+} \mathrm{T}$ lymphocytes in humans. J. Immunol. 166:6952-6963

46. Kremer, L., Estaquier, J., Brandt, E., Ameisen, J.C., and Locht, C. 1997. Mycobacterium bovis Bacillus Calmette Guerin infection prevents apoptosis of resting human monocytes. Eur. J. Immunol. 27:2450-2456

47. Molloy, A., Laochumroonvorapong, P., and Kaplan, G. 1994. Apoptosis, but not necrosis, of infected monocytes is coupled with killing of intracellular bacillus Calmette-Guerin. J. Exp. Med. 180:1499-1509.

48. Klingler, K., et al. 1997. Effects of mycobacteria on regulation of apoptosis in mononuclear phagocytes. Infect. Immun. 65:5272-5278.

49. Balcewicz-Sablinska, M.K., Gan, H., and Remold, H.G. 1999. Interleukin 10 produced by macrophages inoculated with Mycobacterium avium attenuates mycobacteria-induced apoptosis by reduction of TNF- $\alpha$ activity. J. Infect. Dis. 180:1230-1237.

50. Fratazzi, C., et al. 1999. Macrophage apoptosis in mycobacterial infections. J. Leukoc. Biol. 66:763-764.

51. Medeiros, A.I., et al. 2002. Histoplasma capsulatum inhibits apoptosis and Mac-1 expression in leucocytes. Scand. J. Immunol. 56:392-398.

52. Badovinac, V.P., Tvinnereim, A.R., and Harty, J.T. 2000. Regulation of antigen-specific $\mathrm{CD} 8^{+} \mathrm{T}$ cell homeostasis by perforin and interferon- $\gamma$. Science. 290:1354-1358

53. Gomez, F.J., Woodward, E.O., Pilcher-Roberts, R., Gibbons, R.S., and Deepe, G.S., Jr. 2001. V $\beta 6^{+}$and $\mathrm{V} \beta 4^{+} \mathrm{T}$ cells exert cooperative activity in clearance of secondary infection with Histoplasma capsulatum. J. Immunol. 166:2855-2862.

54. Zheng, L., et al. 1995. Induction of apoptosis in mature T cells by tumour necrosis factor. Nature. 377:348-351.

55. Chan, F.K., et al. 2003. A role for tumor necrosis factor receptor- 2 and receptor-interacting protein in programmed necrosis and antiviral responses. J. Biol. Chem. 278:51613-51621.

56. Chakour, R., et al. 2003. Both the Fas ligand and inducible nitric oxide synthase are needed for control of parasite replication within lesions in mice infected with Leishmania major whereas the contribution of tumor necrosis factor is minimal. Infect. Immun. 71:5287-5295.

57. Mousavi, S.A., and Robson, G.D. 2004. Oxidative and amphotericin B-mediated cell death in the opportunistic pathogen Aspergillus fumigatus is associated with an apoptotic-like phenotype. Microbiology. 150:1937-1945

58. Watanabe, N., and Lam, E. 2005. Two Arabidopsis metacaspases AtMCP1b and AtMCP2b are arginine/lysine-specific cysteine proteases and activate apoptosis-like cell death in yeast. J. Biol. Chem. 280:14691-14699.

59. Hotchkiss, R.S., et al. 1999. Prevention of lymphocyte cell death in sepsis improves survival in mice. Proc. Natl. Acad. Sci. U. S. A. 96:14541-14546.

60. Hotchkiss, R.S., et al. 2003. Adoptive transfer of 
apoptotic splenocytes worsens survival, whereas adoptive transfer of necrotic splenocytes improves survival in sepsis. Proc. Natl. Acad. Sci. U. S. A. 100:6724-6729.

61. Zhao, Y.X., et al. 2000. Tumor necrosis factor receptor p55-deficient mice respond to acute Yersinia enterocolitica infection with less apoptosis and more effective host resistance. Infect. Immun. 68:1243-1251.

62. Chen, W., Frank, M.E., Jin, W., and Wahl, S.M. 2001. TGF- $\beta$ released by apoptotic T cells contributes to an immunosuppressive milieu. Immunity. 14:715-725.

63. Freire-de-Lima, C.G., et al. 2000. Uptake of apoptotic cells drives the growth of a pathogenic trypanosome in macrophages. Nature. 403:199-203.

64. Deepe, G.S., Jr., and Gibbons, R.S. 2003. Protective and memory immunity to Histoplasma capsulatum in the absence of IL-10. J. Immunol. 171:5353-5362.
65. Gildea, L.A., Gibbons, R., Finkelman, F.D., and Deepe, G.S., Jr. 2003. Overexpression of interleukin-4 in lungs of mice impairs elimination of Histoplasma capsulatum. Infect. Immun. 71:3787-3793.

66. Lopes, M.F., et al. 1999. Increased susceptibility of Fas ligand-deficient gld mice to Trypanosoma cruzi infection due to a Th2-biased host immune response. Eur. J. Immunol. 29:81-89.

67. Nunes, M.P., Andrade, R.M., Lopes, M.F., and DosReis, G.A. 1998. Activation-induced T cell death exacerbates Trypanosoma cruzi replication in macrophages cocultured with $\mathrm{CD}^{+} \mathrm{T}$ lymphocytes from infected hosts. J. Immunol. 160:1313-1319.

68. Scheller, C., et al. 2002. Caspase inhibitors induce a switch from apoptotic to proinflammatory signaling in CD95-stimulated T lymphocytes. Eur. J. Immunol. 32:2471-2480.

69. Sehra, S., et al. 2005. A role for caspases in con- trolling IL-4 expression in T cells. J. Immunol. 174:3440-3446.

70. Rozman-Pungercar, J., et al. 2003. Inhibition of papain-like cysteine proteases and legumain by caspase-specific inhibitors: when reaction mechanism is more important than specificity. Cell Death Differ. 10:881-888.

71. Newman, S.L., Gootee, L., and Gabay, J.E. 1993. Human neutrophil-mediated fungistasis against Histoplasma capsulatum. Localization of fungistatic activity to the azurophil granules. J. Clin. Invest. 92:624-631.

72. Cain, J., and Deepe, G.S., Jr. 1998. Evolution of the primary immune response to Histoplasma capsulatum in murine lung. Infect. Immun. 66:1473-1481.

73. McCormack, F.X., et al. 2003. Macrophage-independent fungicidal action of the pulmonary collectins. J. Biol. Chem. 278:36250-36256. 